with translational accommodation, and does not involve any assumptions about specific heat.

Since the deflexion of the balance depends on the impact momentum and the degree of its reversal at the balance arm, an assumption about the momentum accommodation coefficient of the latter must be made. It must lie between zero and unity, and results have been calculated on both assumptions, though the latter is much more likely, as the surface of the balance arm has not been specially cleaned.

Preliminary exporiments on a tungsten wire in helium, argon and nitrogen at pressures of order $10^{-3}$ torr give the following values of $\alpha$ at $2,800^{\circ} \mathrm{K}$-a temperature at which the surface of the tungsten is likely to be clean-helium, $0.07-0.12$; argon, $0.23-0.50$; nitrogen, $0.35-0.72$, the range of values resulting from the two extreme assumptions mentioned here.

The experiments have been performed with the tungsten wire in a fixed position relative to a carefully designed system of aperturos, so that only molecules coming from an isothermal and geometrically defined part of the tungsten wire can reach the balance arm directly.

Future experiments are being designed so that the heated body (for example, tungsten) can be replaced at will by the aperture of a furnace from which the issuing molecules can be assumed to bo in thermal equilibrium. The degree of momentum accommodation on the balance arm can then be directly determined, made to approach unity by suitable surface treatment, and the foregoing ambiguities removed.

L. G. CARPENTER

D. E. HUMphries

W. N. MAIR

Royal Aircraft Establishment, Farnborough, Hants.

\section{Phonon Concept at High Temperatures}

To deduce an expression for the lattice thermal con. ductivity it is usual to consider the volume of the solid as occupied by a 'phonon gas', and then to find the resist. ivities due to the scattering of the phonons by other phonons, electrons and structural defects ${ }^{1}$.

Such theories assume that the phonons behave like particles, except that their number is not conserved. However, each phonon is really a group of waves. At high temperatures, defined by $\omega \tau<1$, where $\omega$ is the angular frequency and $\tau$ the lifetime of the interacting phonon, only part of this wave train may be affected by a collision. Thus the phonon-quasi particle duality sometimes becomes invalid at high temperatures.

This is corroborated by experimental evidence ${ }^{2}$ : a group at the Massachusetts Institute of Technology recently found that the thermal conductivity of solid solutions of $\mathrm{Mg}_{2} \mathrm{~Pb}_{x} \mathrm{Sn}_{1^{-x}}$ for $0 \leqslant x \leqslant 30$ per cent at room temperature did not follow the functional form suggested by Klemens's ${ }^{3}$ equation. It becomes necessary to rely on phenomenological theories ${ }^{4}$ to relate thermal conductivity data at high and low temperatures ${ }^{5,6}$. The term 'phonon' at high temperatures is frequently found in the literature when it would be better to speak of lattice waves $^{7,8}$. Thus the limits of application of the phonon concept need further investigation.

\section{Dovglas Probert}

Welsh College of Advanced Technology,

$$
\text { Cardiff. }
$$

${ }^{1}$ Ziman, J. M., Electrons and Phonons (Oxf. Univ. Press, 1960).

${ }^{2}$ van Houten, S., Philips Res. Rep., 433 (1960).

3 Kleme, P.

' Klemens, P. G., Solid State Physics, 7, 1 (A

${ }^{5}$ Slack, G. A., and Glassbrenner, C., Phys. Rev., 120, 3 (1560).

6 Agrawal, B. K., and Verma, G. S., Phys. Rev., 126, No. 1 (1962)

Tavernier, C. R., C.R. Acad. Sci., Paris, 245, 20, 1705 (1957); 247, 16, 1179 (1958)

${ }^{8}$ Aigrain, P., M.I.T. Quart. Rep., Nos. 54 and 55 (1959); No. 56 (1960).

\section{GEOLOGY}

\section{Velocity of Sliding of an Ice-fall}

During the Nepal Himalaya P-29 (7,835 m) Expedition of Osaka University Mountaineering Club, 1961, we had some experience on sliding and avalanches of an active ice-fall; analysing photographs taken by a Canon $2,000 \mathrm{~mm}$ telephotographic lens from the base camp at $4,400 \mathrm{~m}$ high. Fig. 1 is a series of photographs taken at: $(a)$ May $10,1^{\circ} 30^{\prime}$ p.m.; (b) May $11,9^{\circ} 30^{\prime}$ a.m.; (c) the same day $11^{\circ} 30^{\prime}$ just after a small avalanche. By comparing the photographs $(a)$ and $(b)$ we can see that the glacier ice slid down as shown in Fig. 2. The distance of sliding on the original photograph was $2.0 \mathrm{~mm}$. As the distance from the base camp to the ice-fall was $4 \mathrm{~km}$, it corresponds to $4 \mathrm{~m}$. As the estimated slope was $60^{\circ}$, the speed of sliding of the ice-fall became $6 \mathrm{~m} /$ day. Evidently this value is too large compared with the usual

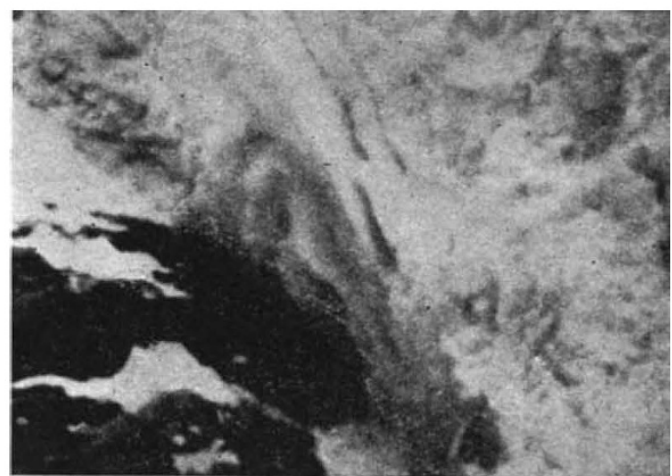

(a)

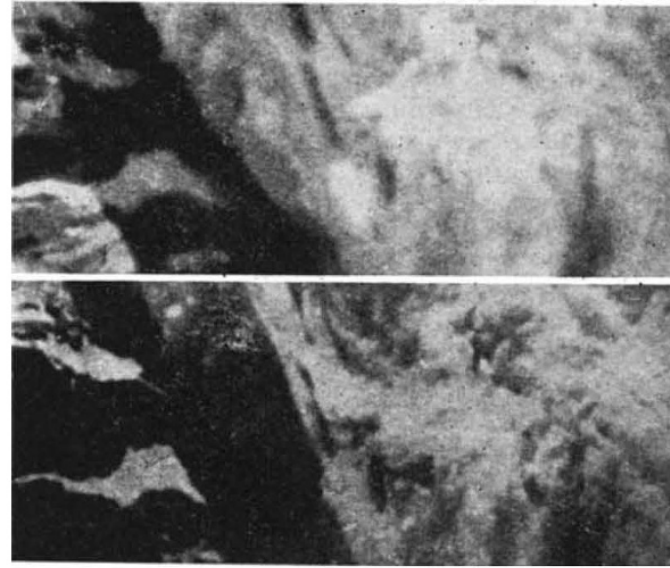

Fig. 1

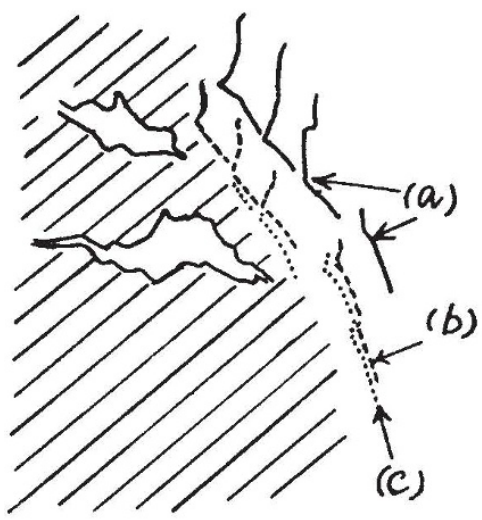

Fig. 2 